\title{
CARACTERIZAÇÃO GEOAMBIENTAL DA MICRORREGIÃO DO SERIDÓ ORIENTAL DO RIO GRANDE DO NORTE
}

\author{
José Gilberto Olimpio Bezerra Júnior \\ Graduando em Geografia - CEFETRN.gil_olimpio@hotmail.com \\ Nubelia Moreira da Silva \\ Professora do CEFETRN. nubelia@cefetrn.br
}

\section{RESUMO}

A microrregião do Seridó Oriental do Rio Grande do Norte constitui a área do presente estudo que se situa na parte centro-sul deste Estado, da qual fazem parte os seguintes municípios: Acari, Carnaúba dos Dantas, Cruzeta, Currais Novos, Equador, Jardim do Seridó, Ouro Branco, Parelhas, Santana do Seridó e São José do Seridó, totalizando juntos 3.825,73 Km² de área territorial, equivalendo a 7, 24\% de todo o território do Estado. Esse subespaço do Rio Grande do Norte faz parte da região semi-árida ou do polígono das secas nordestinas e diferencia-se de outras áreas do Estado, dentre outros fatores, por abranger uma enorme área fustigada por secas constantes. Ultimamente, poucos estudos teóricoempíricos têm sido realizados sobre esse recorte espacial objetivando identificar, mapear e analisar os componentes geoambientais e a biodiversidade dessa importante região geográfica do Estado, nem tampouco se tem atualizado suas informações geográficas, nas mais diversas dimensões. Dessa maneira, é importante fazer um estudo da região, destacando a formação geológica e geomorfológica que é predominantemente constituída de formações antigas e topografia suave e ondulada, dispondo de solos, de um modo geral, formados por rochas cristalinas e apresentando grandes limitações, devido à pequena capacidade de retenção da água e a susceptibilidade à erosão. Juntando-se a isso, tem-se o clima predominante muito quente e com temperaturas superiores a $27^{\circ} \mathrm{C}$ e uma vegetação de caatinga. Para desenvolver este trabalho, conduzimos um levantamento de informações cartográficas e bibliográficas da área, aulas de campo, interpretação e a análise dos dados levantados e a disposição destes em um artigo.

PALAVRAS-CHAVE: Seridó Oriental; geografia física; componentes geoambientais. 


\section{CARACTERIZAÇÃO GEOAMBIENTAL DA MICRORREGIÃO DO SERIDÓ ORIENTAL DO RIO GRANDE DO NORTE}

\section{INTRODUÇÃO}

Situado na área Centro-Sul do estado do Rio Grande do Norte e inserido na Mesorregião Central Potiguar, a Microrregião do Seridó Oriental faz divisa ao Sul e ao Leste com a Paraíba, ao Norte e ao Oeste, respectivamente, com as Microrregiões da Serra de Santana e do Seridó Ocidental. Encontram-se inseridos nesta Microrregião os municípios de Acari, Carnaúba dos Dantas, Cruzeta, Currais Novos, Equador, Jardim do Seridó, Ouro Branco, Parelhas, Santana do Seridó e São José do Seridó que estão ilustrados na figura 1.

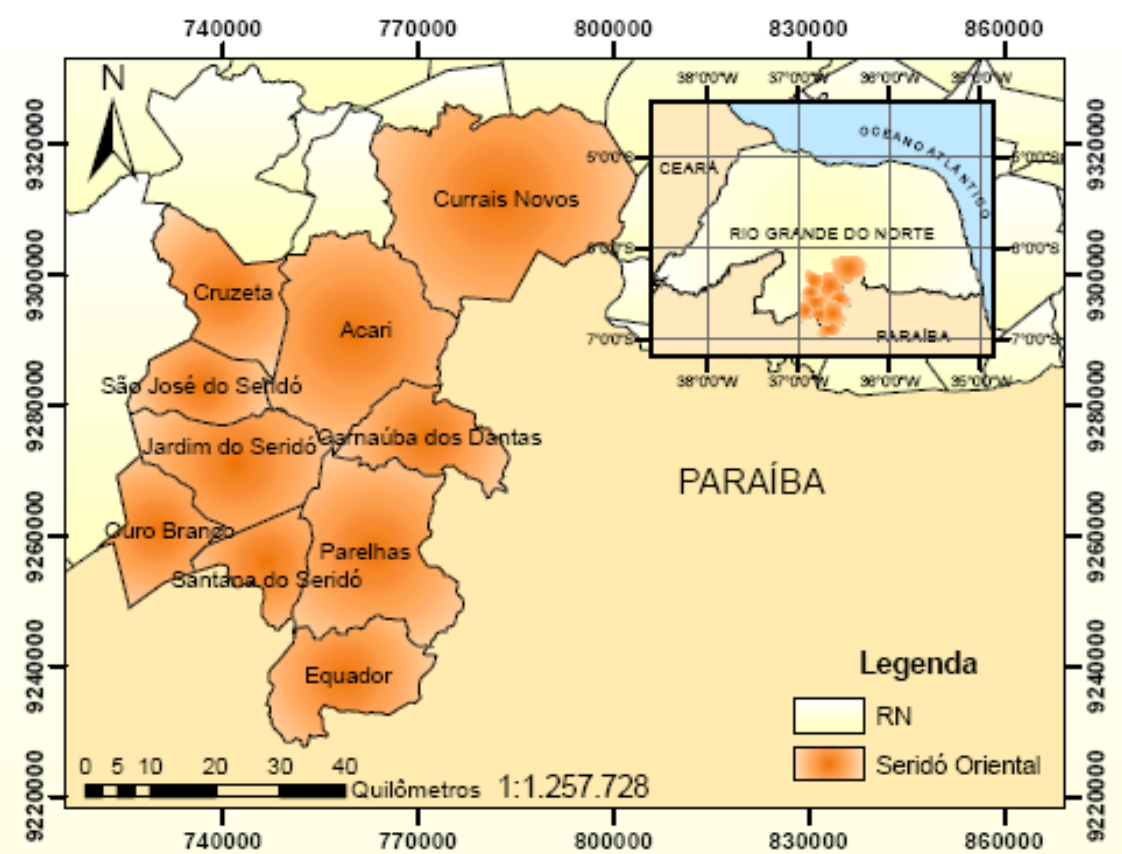

\section{Figura 1: Localização do Seridó Oriental no Rio Grande do Norte. Fonte: IBGE. Mapa adaptado - 2007. Elaborador: GARCIA, Robson S.}

Esse subespaço do Rio Grande do Norte é caracterizado pelo bioma da caatinga, de clima semi-árido, que apresenta secas prolongadas, um relevo com formações antigas, solos facilmente erodiveis e um sistema hidrológico com baixo potencial. Nesse contexto, tornase importante compreender suas características geoambientais para que suas potencialidades sejam utilizadas de forma sustentável, evitando assim degradações ambientais.

As razões da realização deste trabalho estão centradas principalmente na atualização dos conhecimentos geográficos sobre a produção e reprodução dessa sub-região potiguar. Outro fato justificativo da realização desta pesquisa recai sobre a ausência de dados elaborados pelo próprio Núcleo de Estudos do Semi-Árido (NESA) no que se refere às características geográficas do sertão potiguar. A base não dispõe de um banco de dados e informações próprias e esta é uma excelente oportunidade para iniciarmos a montagem de um banco de informações consistente para o nosso núcleo de pesquisa, o que irá auxiliar nos estudos e pesquisas futuras não só do Centro Federal de Educação Tecnológica do Rio Grande do Norte (CEFETRN), mas também poderá ser disponibilizado para qualquer pesquisador interessado no tema. 
Os objetivos que buscamos são primariamente analisar os componentes geoambientais (relevo, solo, clima, hidrografia e vegetação) da microrregião do Seridó Oriental Potiguar atentando para a interdependência entre estes elementos. Secundariamente, identificar as diversas formas de relevo e sua distribuição no espaço da microrregião; realizar levantamento a respeito das condições climáticas e sua interferência no regime hidrográfico da área em estudo; analisar o comportamento do sistema da rede hidrográfica no mosaico em destaque; caracterizar a vegetação presente na área de estudo e identificar os principais tipos de solo encontrados na microrregião em análise.

Para alcançarmos essa meta, utilizamos técnicas de pesquisa de levantamento e coleta das informações cartográficas e bibliográficas sobre a temática e a área de estudo. O trabalho de campo (pesquisa direta) foi realizado através de observação in loco, o que permitiu a obtenção dos dados que compõem esta pesquisa. Coletados e tratados esses dados, fez-se a análise e interpretação dos mesmos, bem como sua interação com as informações obtidas nas demais fontes.

\section{RELEVO}

A estrutura geológica do Seridó Oriental data do Pré-Cambriano, compreendida basicamente por rochas antigas representadas predominantemente pelas rochas ígneas ou magmáticas e as metamórficas, sendo as duas comumente denominadas de terrenos cristalinos. Essa estrutura ocorre em grande parte do território do Estado e principalmente na mesorregião central (FELIPE e CARVALHO, 1999, p.39).

Essa estrutura litológica justifica a presença e conseqüentemente a extração de minerais que possuem importância econômica como: Argilas, Barita, Berilo, Cassiterita, Caulim, Tantalita, Mica e Scheelita. Destaca-se neste contexto, o município de Currais Novos onde predomina a extração da Scheelita (FELIPE e CARVALHO, Op. cit., p.39-46).

Outra atividade de destaque da região são as indústrias ceramistas (olarias), como afirma Lucena, o coordenador nacional do Grupo de Trabalho de Combate à Desertificação e da Articulação do Semi-Árido Brasileiro (ASA), “o Seridó tem 66 cerâmicas, espalhadas em 14 municípios, representando quase 50\% das cerâmicas do estado. Somente em Parelhas existem 24 cerâmicas' (GOMES, 2006, p.12) que contribuem para o desmatamento da cobertura vegetal, sendo um dos fatores responsáveis pela intensificação do fenômeno da desertificação.

A topografia da área estudada é formada pela Depressão Sertaneja e pelo Planalto da Borborema. O primeiro é plano, constituído por uma superfície de erosão (sedimentar) desenvolvida a partir de fatores exógenos tais como o clima e é mais comumente encontrado em fundos de vales abertos e/ou em colinas rasas, sendo ainda essa superfície constituída por inselbergs, esses últimos são resultantes de levantamentos antigos, mostrando cristais ou maciços rejuvenescidos e possuindo altitudes inferiores a $100 \mathrm{~m}$ (ROSS, 2003), aonde apresentam afloramentos graníticos. A figura 2 mostra o perfil do relevo da microrregião em análise. 


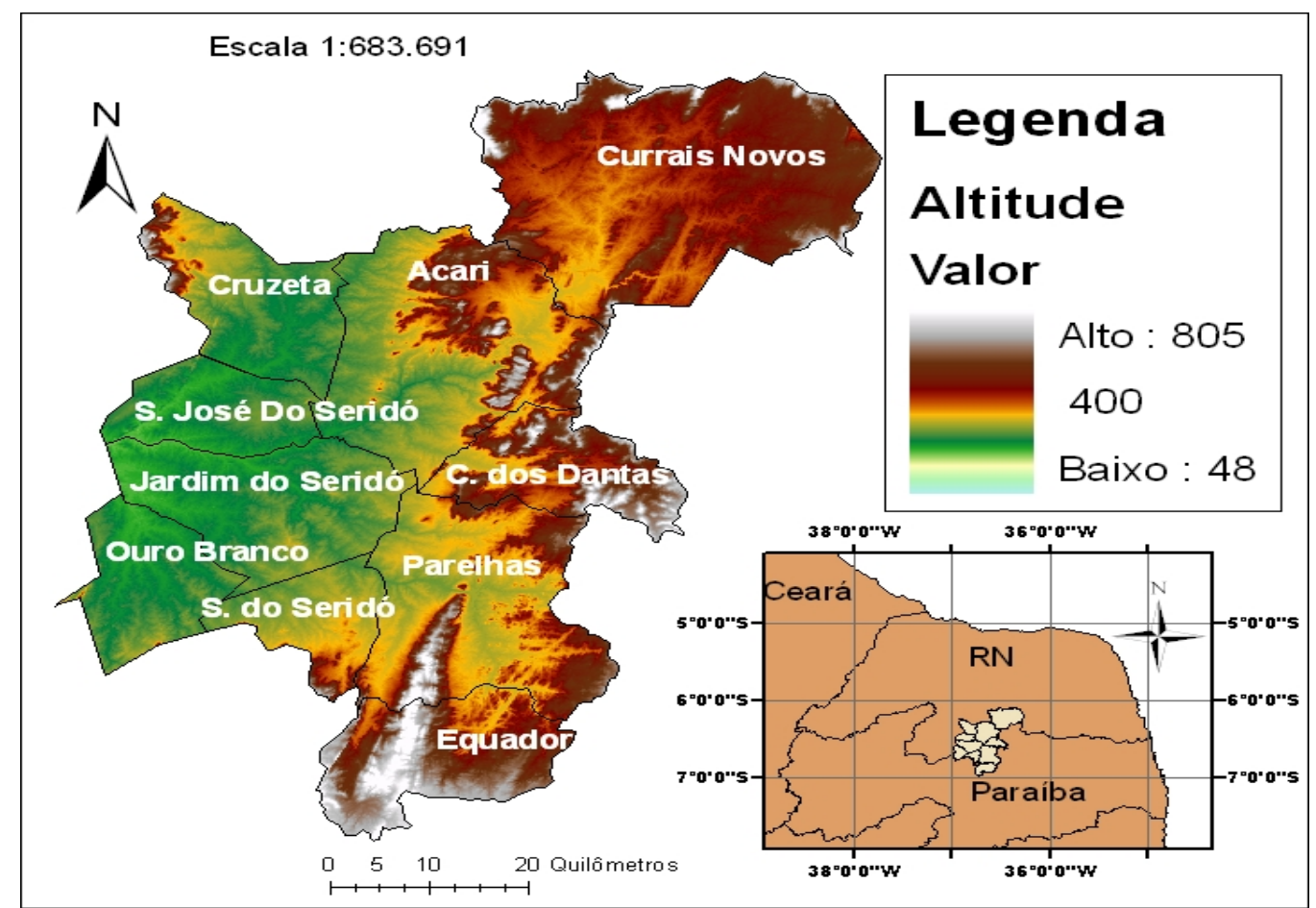

Figura 2: Relevo do Seridó Oriental, BEZERRA Jr, 2007. Mapa Adaptado do IBGE/EMBRAPA, 2006.

Já o Planalto da Borborema está compreendido em segmentos dos dobramentos das rochas Pré-cambrianas soerguidas em forma de abóbodas (ROSS, Op. cit.). Esses se comportam como maciços antigos intensamente trabalhados por processos erosivos ao longo do Terciário, com altitudes que variam entre 50 a 800 metros, apresentando geralmente formas com topo retilíneos ou convexos esculpidos em litologias do cristalino.

A Depressão Sertaneja da região contorna o Planalto da Borborema nas suas partes mais baixas, formando vales. Esses vales são facilmente perceptíveis à observação, pois a maioria dos municípios encontra-se entre chapadas e chapadões ou na própria Depressão. O Planalto ainda apresenta um baixo potencial hídrico sub-superficial (SOUZA et al, 1996, p.13). A figura 3 mostra um exemplo típico do relevo do Planalto.

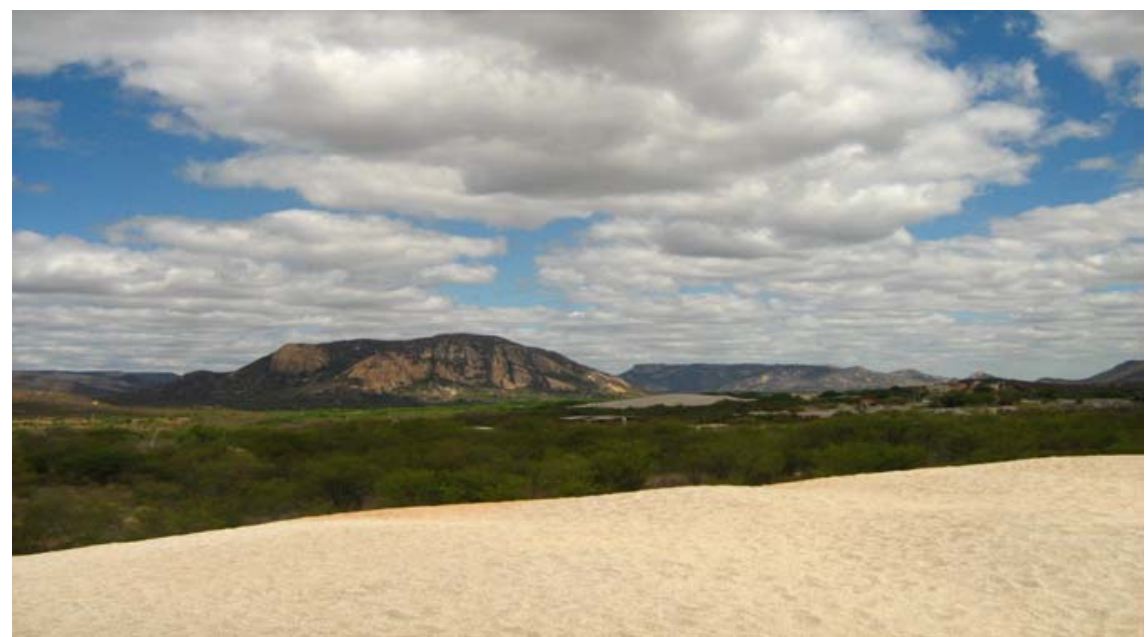

Figura 3: Relevo típico do Planalto da Borborema. Bezerra, Currais Novos/RN, 2007. 
Essas características do relevo refletem as condições climáticas locais que determinam à formação dos tipos de solos advindos dos fatores erosivos do cristalino e o sistema hidrológico com baixo potencial que emergem na região, evidenciando os agentes endógenos e exógenos que agem sobre o ambiente e o tipo de utilização antrópica decorrente.

\section{SOLO}

As condições geomorfológicas presentes no Seridó Oriental explicam as características dos solos da região. Por sua vez, estes são

(...) resultante da ação integrada do clima e organismos sobre o material de origem, condicionado pelo relevo em diferentes períodos de tempo, o qual apresenta características que constituem a expressão dos processos e dos mecanismos dominantes na sua formação (GUERRA e CUNHA, 2004, p.66).

Conhecer o tipo de solo e suas características é fundamental, principalmente devido a sua importância socioeconômica e ambiental. Mas frequentemente dar-se importância apenas à camada superficial ou arável e desconhece-se o que está abaixo dos primeiros centímetros da superfície. Isso conduz a utilização inadequada, podendo ocorrer depauperização do solo e a degradação ambiental (GUERRA e CUNHA, Op. cit., p.68-70).

Por tanto, o entendimento de sua formação e composição é essencial para melhor utiliza-lo e evitar a exaustão deste recurso natural indispensável à sustentabilidade socioambiental. Os tipos de solos mais freqüentes na região estudada são os: Luvissolos Crômicos, Neossolos Litólicos, Planossolos Nátricos e o Latossolo Vermelho-Amarelo (Embrapa, 1999).

Luvissolos Crômicos ocorrem nos municípios de Acari, Cruzeta, Currais Novos, Jardim do Seridó, Ouro Branco, Santana do Seridó, São José do Seridó e Parelhas. Esse tipo de solo apresenta ondulações formando vales em "V" abertos, com suas vertentes medindo dezenas de metros, relacionando-se com o relevo de planalto, apresentando vales e inselbergs. É um solo raso, de coloração avermelhada viva devido à argila (oxidação do ferro), com saturação de bases muito alta, praticamente neutro, isto é, permitindo maior aproveitamento dos nutrientes e dificultando o surgimento de elementos tóxicos a agricultura. Ainda apresentando fases pedregosas (horizontes cascalhentos), suscetível à erosão e com bom nível de drenagem, o que significa dizer que a água que o solo absorve é facilmente removida pela evaporação (GUERRA e CUNHA, Op. cit, p.92).

Dessas características já comentadas, as que melhor explicam sua limitação agrícola é a sua falta de água, devido a efeitos climáticos, a sua susceptibilidade a erosão e por ser um solo pedregoso, dificuldade no manejo agrícola. Nessas condições, a forma de agricultura aconselhada e/ou praticada são as de ciclo longo, tais como algodão arbóreo, sisal, coco e entre outros (IDEMA, 2006).

Outro tipo de solo muito freqüente no Seridó é o Neossolo Litólico. Trata-se de um solo pouco desenvolvido, raso ou muito raso (cerca de $40 \mathrm{~cm}$ de profundidade) e assentado diretamente sobre rochas ou materiais da rocha do embasamento cristalino. Isso ocasiona o aparecimento constante de pedregosidade e rochosidade na superfície, sendo comumente 
encontrado afloramentos das rochas. Por possuir uma drenagem que vai de moderada a acentuada, denota que a água que este absorve é lentamente perdida, mas que mantêm o solo úmido por um curto período de tempo, sendo comum à susceptibilidade a erosão (VIEIRA, 1983). Tendo também, assim como os Luvissolos Crômicos, formações relacionadas com as caatingas hiper e hipoxerófilas. Os solos litólicos possuem um baixo potencial agrícola devido a sua pouca profundidade. Essa condição reduz o volume de terra disponível para o ancoramento das plantas e a retenção de umidade. Ao Neossolo é recomendado seu uso para pastagens devido à limitação para o crescimento radicular em profundidade da maioria das plantas (PRADO, 2007). Os municípios que apresentam essa formação do solo são: Acari, Currais Novos, Equador, Carnaúba dos Dantas, Parelhas e Santana do Seridó.

O Planossolo Nártico é um exemplo de solo típico de relevo plano, apresentando geralmente altos teores de sódio. Isso contribui para a salinidade nos reservatórios de água aonde ele ocorre. Essas características prejudicam a agricultura e tornam a água salobra e imprópria para consumo humano. Este solo apresenta desargilização no primeiro horizonte e concentração de argila nos posteriores devido ao acumulo de argila que a oscilação do lençol freático provoca. Isto ocorre pela insuficiência de drenagem, tornando a remoção da água lenta, mantendo o solo molhado por um longo período. Apesar de possuir altas taxas de lençol freático esta condição não é permanente. É um solo pouco poroso com alta impermeabilidade que provoca efeitos erosivos nas proximidades de redes de drenagem (VIEIRA, 1983).

A partir de observações da figura 4, Currais Novos é o único município que apresenta o Latossolo Vermelho-Amarelo, mesmo assim em apenas uma pequena porção a Noroeste e Norte.

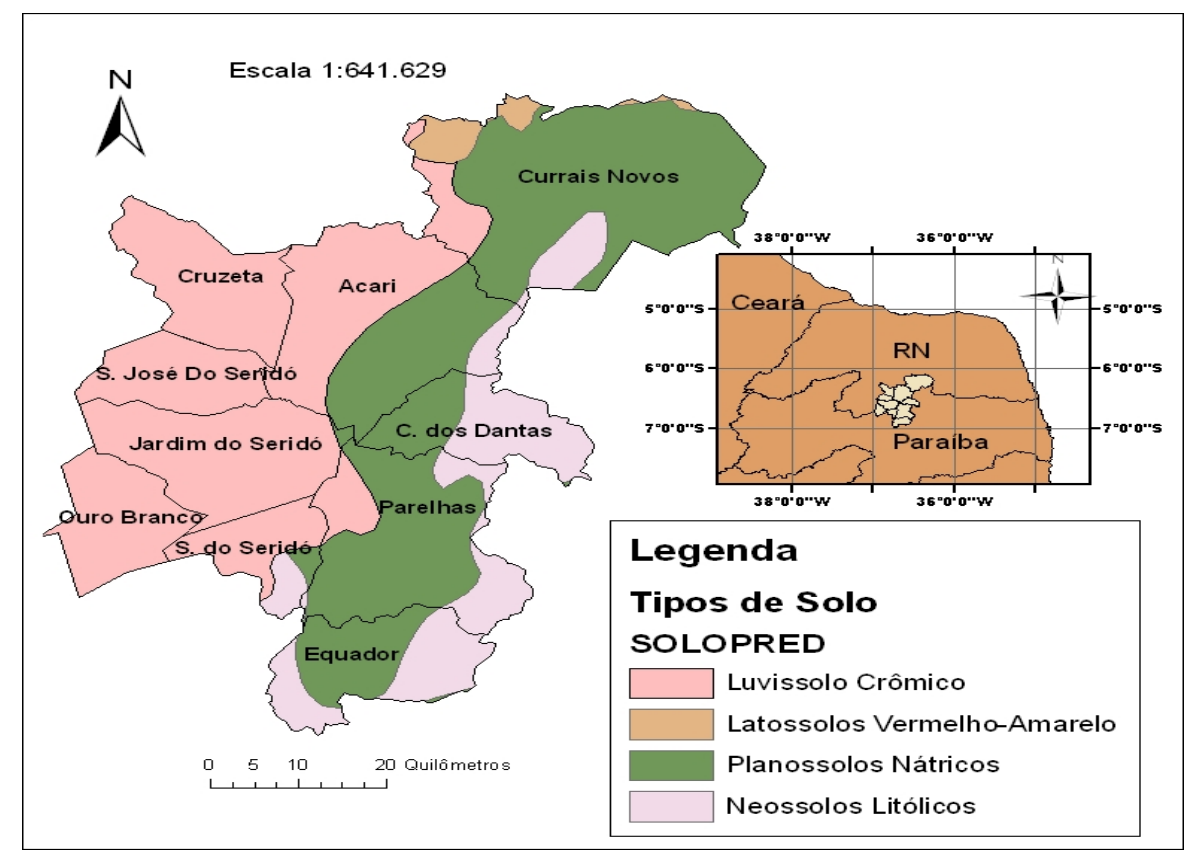

Figura 4: Mapa de Solos, Bezerra Jr, 2008. Mapa adaptado da EMBRAPA/IBGE, 2007

Esse solo possui cor vermelho-amarelada, com estrutura granular maciça com predomínio de minérios de ferro como goetita e hematita que aumenta conforme o solo é mais 
avermelhado. A estrutura é moderadamente desenvolvida em blocos subangulares que se definem por fragmentos de rochas erodidas que possuem uma mistura de faces arredondadas planas com muitos vértices arredondados (GUERRA e CUNHA, 2004, p.102) e são profundos (cerca de 100 a $200 \mathrm{~cm}$ ). Esse tipo de solo ocorre mais predominantemente em relevo plano à suave ondulado e sua limitação em fertilidade está na dificuldade de retenção de nutrientes nos solos. Porém eles não apresentam restrições à agricultura intensiva, apenas deve-se ter cuidado com o manejo em função de sua estrutura pesada, pois podem ocorrer processos erosivos e formação de camadas adensadas no solo (AMARAL et al, 2000).

\section{CLIMA}

Para determinar um tipo climático, levam-se em conta os índices médios de pluviosidade e sua distribuição, pois têm efeitos sobre a vegetação tanto a drenagem natural e a umidade do solo, como também a temperatura, o relevo, a umidade relativa do ar, as massas de ar e a evapotranspiração. Sendo essa última a quantidade de água do solo e vegetação que evapora para a atmosfera (FELIPE e CARVALHO, 1999).

Segundo o Instituto de Desenvolvimento Econômico e Meio Ambiente (IDEMA), o clima do Seridó Oriental se subdivide em 3 tipos: Semi-Árido Rigoroso, Semi-Árido e SubÚmido Seco representados na figura 5.

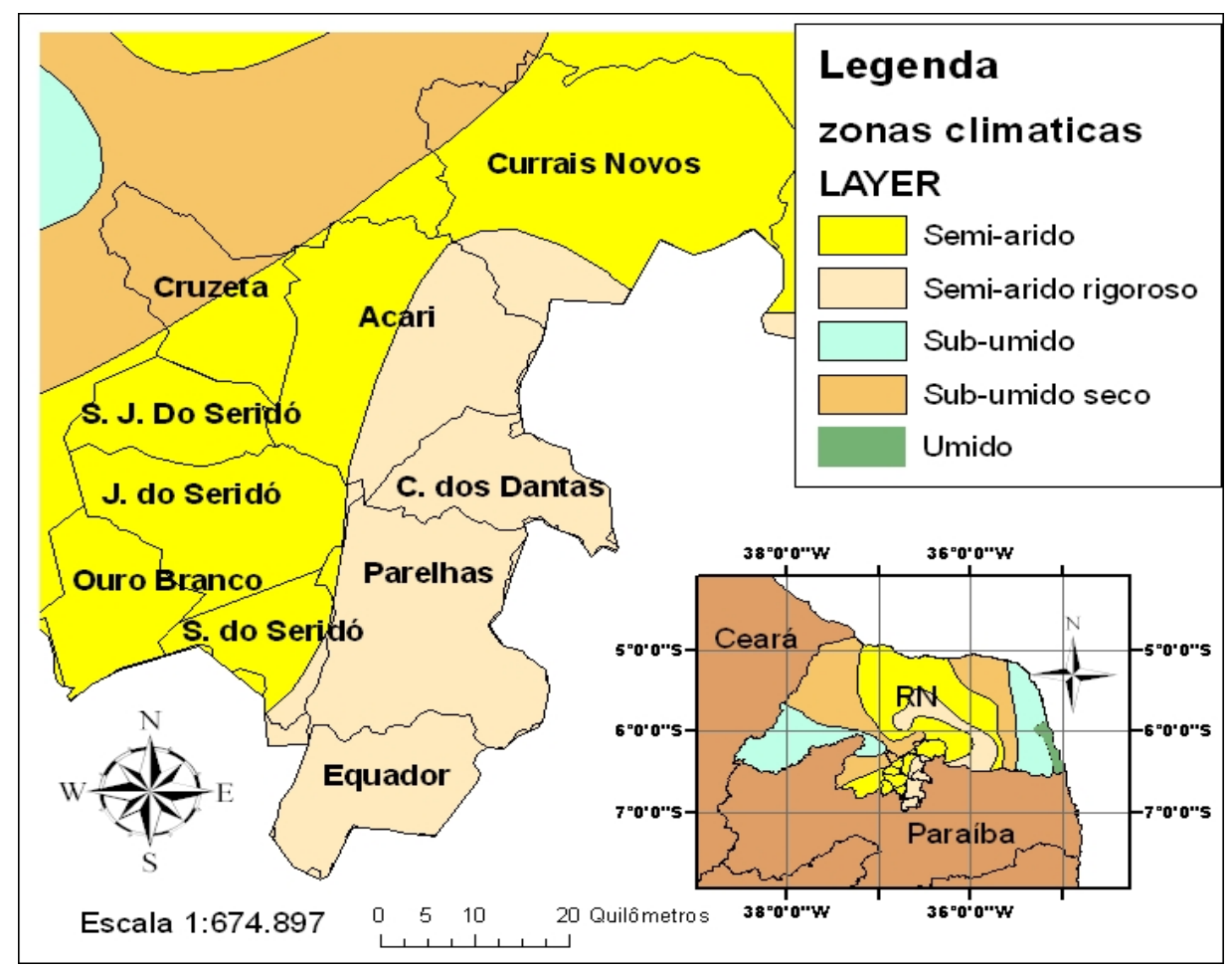

Figura 5: Mapa do clima, Bezerra Jr, 2007. Mapa adaptado do IDEMA, 2005/2006.

O semi-árido rigoroso assim é denominado devido a pouca chuva e esta é distribuída de forma irregular no território. Sua pluviosidade média ronda aos $400 \mathrm{~mm}$ e sua evapotranspiração não gera excedente de água durante todo o ano, esse tipo climático abrange $18 \%$ da área do Estado. Já o semi-árido tem variação pluviométrica de $400 \mathrm{~mm}$ a 
$600 \mathrm{~mm}$, porém suas chuvas também são irregulares, mas geralmente se concentram em dois a quatro meses por ano. Essas chuvas geram um excedente inferior a $40 \mathrm{~mm}$ de água durante o ano inteiro, e abrange $57 \%$ do Estado, percorrendo o interior até o litoral setentrional. Já o Sub-Úmido Seco abrange do litoral oriental as áreas serranas do estado com variações pluviométricas de 150 a $450 \mathrm{~mm}$ durante os meses de março a junho aproximadamente. Essa característica decorre porque a "[...] topografia liga-se com mudanças concomitantes na influência exercida sobre o fluxo de ar [...]” e "[...] outros elementos do tempo atmosférico, como a temperatura e a precipitação" (AYOADE, 2001, p.95).

Ross (2003, p.104) explica que um fator provável de influência no clima do Seridó são as massas de ar continental-tropical, estas sofrem altas pressões no trópico. Dessa maneira, dificulta a penetração da massa equatorial continental (EC), da tropical atlântica (TA) e inclusive a frente polar atlântica (FPA) originando climas semi-áridos com temperaturas altas e oscilação térmica anual moderada. Essa informação é complementada por Pessoa (1971) quando afirma que a massa de ar que cobre o Nordeste é quente por vir de ventos da massa Tépida Calaariana (TK) provenientes do deserto de Calaari (África do Sul) carregados através do atlântico pelos ventos alísios que chegam pelo sudeste do Nordeste. Assim, se não houvessem eventuais perturbações das outras massas de ar (EC, FPA, TA) o Nordeste seria um deserto.

A temperatura média anual do Seridó é de $27,5^{\circ} \mathrm{C}$ e com máximas de $33{ }^{\circ} \mathrm{C}$ e mínimas de $18{ }^{\circ} \mathrm{C}$ (IDEMA, 2006). Com uma insolação de aproximadamente 2.455 horas/ano e sujeito à influência dos ventos alísios secos do Nordeste (IDEMA, 2006), o clima do Seridó é seco, com altas taxas de evapotranspiração que contribuem para a formação de rios temporários e pouca retenção de água no solo. Isto dificulta a produção agrícola em geral e a vida da população local. Dessa maneira, torna-se necessária a construção de adutoras e barragens que amenizem a situação.

\section{HIDROGRAFIA}

A região do Seridó Oriental é banhada pela bacia do Rio Piranhas - Açu, que ocupa uma superfície de $17.498,5 \mathrm{~km}^{2}$, correspondendo a cerca de 32,8\% do Estado do RN, e abrange 33 municípios perfazendo toda a mesorregião central e parte da agreste e oeste. Sua cabeceira dar-se na Serra do Bongá, na Paraíba, adentra no RN pelo município de Jardim de Piranhas e deságua no oceano Atlântico nas proximidades da cidade de Macau (GRUBEN e LOPES, 2001). No Seridó Oriental, pertencendo à bacia Piranhas-Açu, está a sub-bacia do Rio Seridó. Esta cobre toda a área estudada, e entre os seus principais afluentes destacam-se: Rio Acauã, Carnaúba, São José, Barra Nova, Rio das Cobras e Sabugi.

Como explica Guerra e Cunha (2003), um sistema hidrográfico de drenagem caracterizase pela formação de encostas, topos, fundos de vales, canais, corpos de água subterrânea entre outros. Essas características interligam-se formando uma superfície que drena água, sedimentos e materiais para o canal fluvial.

Dessa maneira, a bacia Piranhas - Açu pode ser caracterizada de duas diferentes formas: a drenagem nas áreas do Planalto e a da Depressão. Nas áreas do Planalto da Borborema, esta possui uma drenagem radial, que escoa a partir de um ponto topograficamente alto, 
significando que a maior parte dos rios do Seridó Oriental tem suas cabeceiras na borda do planalto. Já na área da Depressão, os rios apresentam um padrão de drenagem dentrítica, sendo perceptível em mapas, nos cursos dos rios, a aparência de raízes de árvores. Esses rios são bastante retilinizados, denotando uma estrutura marcadamente controlada pelos contornos do Planalto (RIO GRANDE DO NORTE, 1997), o que visualizamos na figura 6.

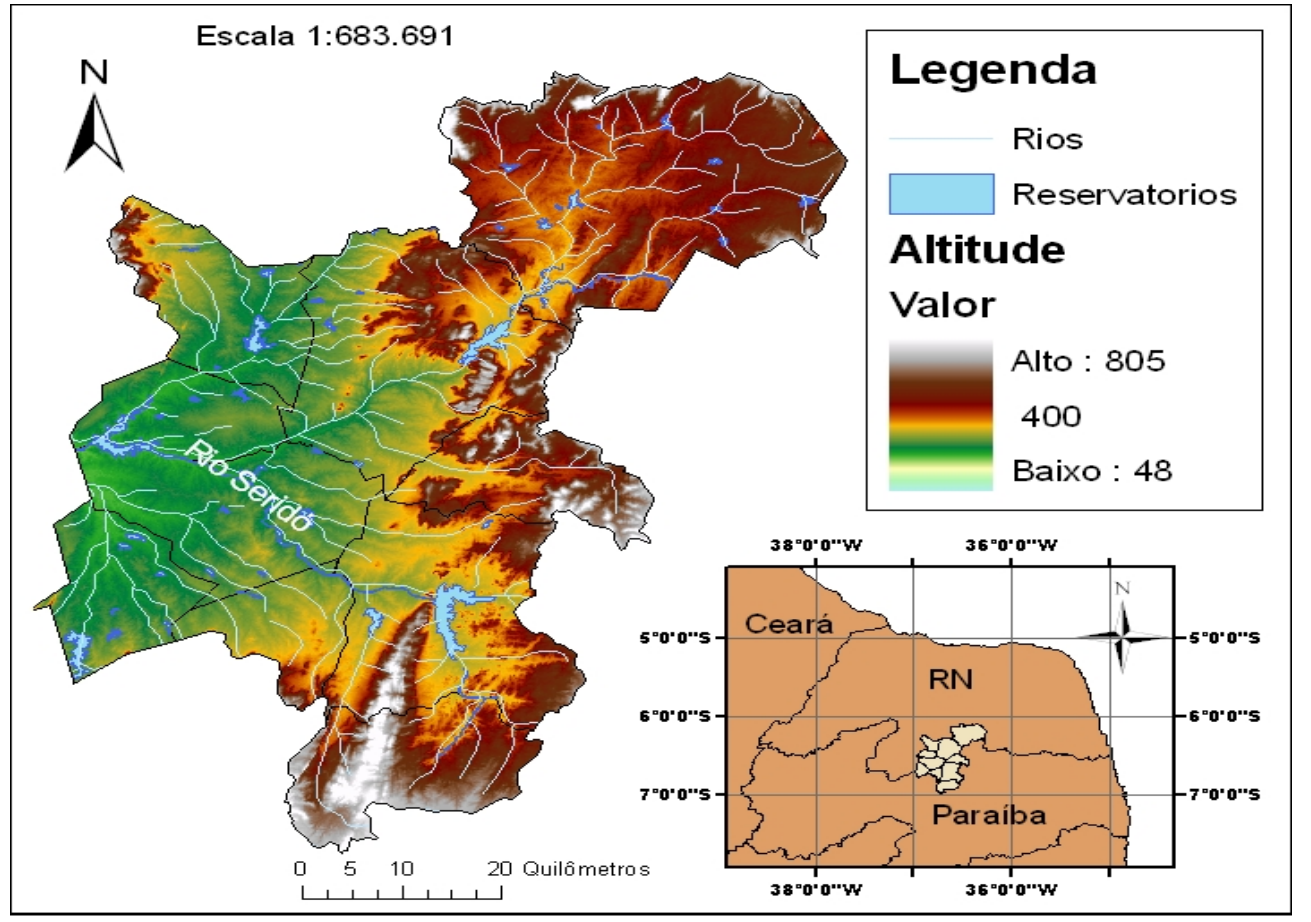

Figura 6: Hidrografia relacionada com o relevo. BEZERRA Jr. 2007. Mapa Adaptado da EMBRAPA/IDEMA, 2007.

Devido ao solo do Seridó ser de formação cristalina, denota-se assim o baixo potencial hídrico sub-superficial da bacia e sua fragilidade, ressaltando a importância de evitar a retirada de cobertura vegetal nas encostas de rios, pois o solo pode erodir e assorear os mesmos. Outros fatores naturais que contribuem para o baixo potencial hídrico, além do solo, é o clima semi-árido com sua alta taxa de insolação hora/dia. Dessa maneira, o déficit hídrico é estimado em 2.022 l/s para o ano 2010, mas 90\% desse déficit originam-se da sub-bacia do rio Seridó (GRUBEN e LOPES, Op. cit).

Esses elementos explicam o fato da bacia ser formada na maior parte por rios temporários. As características naturais da bacia que abastece o Seridó as tornam incapazes por si só de suprir as necessidades de toda a população. Por isso, a hidrografia seridoense é marcada por reservatórios, como os de Cruzeta, localizado no município de Cruzeta que armazena 35.000.000 $\mathrm{m}^{3}$ de água e que represa o Riacho São José, servindo para abastecer comunidades rurais e urbanas da região, para agricultura irrigada e pequenas culturas à jusante; Zangarelhas em Jardim do Seridó, capaz de armazenar $7.916 .00 \mathrm{~m}^{3}$ e represa o Rio da Cobra, abastecendo assim as comunidades locais, as culturas de vazantes, pisciculturas e irrigação difusa; Caldeirão de Parelhas, em Parelhas, que armazena $10.195 .600 \mathrm{~m}^{3}$ e represa o Riacho dos Quintos, abastecendo Santana do Seridó e servindo para cultivo de vazantes e piscicultura; Boqueirão de Parelhas, também em Parelhas, com capacidade para 85.012.750 $\mathrm{m}^{3}$ de água, auxilia na perenização do curso do Rio Seridó, abastecendo Parelhas e outras comunidades e também sendo útil para piscicultura, exploração de cultivos agrícolas e lazer. 
Destacam-se ainda os reservatórios Marechal Dutra em Acari, que armazena 40.000.000 $\mathrm{m}^{3}$ e represa o Rio Acauã; Dourado em Currais Novos, com armazenamento de 10.321.600 $\mathrm{m}^{3}$ e represamento do Rio Currais Novos, destinando-se ao abastecimento de água da cidade de Currais Novos, o cultivo de culturas de vazante e a atividade de piscicultura; Esguicho em Ouro Branco, armazena 21.709.345 $\mathrm{m}^{3}$ e pereniza o Rio Quipauá, assim abastecendo comunidades rurais e urbanas, servindo para piscicultura e cultivo de culturas de vazante; Passagem das Traíras em São José do Seridó, que armazena $48.858 .100 \mathrm{~m}^{3}$ e destina-se a perenização do Rio Seridó e ao lazer. (RIO GRANDE DO NORTE, 2006). Mesmo assim, esses açudes abastecem apenas 43,6\% dos domicílios existentes (RIO GRANDE DO NORTE, 1997).

Ainda assim, foi necessária a construção da Barragem Armando Ribeiro Gonçalves, para garantir a vazão mínima vinda do estado da Paraíba que é cerca de $4,5 \mathrm{~m}^{3} / \mathrm{s}$ (RIO GRANDE DO NORTE, Op. cit), devido a montante de água diminuir consideravelmente no Seridó. E, ainda, o estado da Paraíba construiu o reservatório Coremas-Mãe D'Água no principal afluente do rio Piranhas, de forma a perenizar o afluente e um trecho do rio, garantindo a vazão mínima que entra no Estado do Rio Grande do Norte, pois na região do Seridó, as chuvas tendem a diminuir, dessa forma, para garantir não só o abastecimento da Barragem Armando Ribeiro Gonçalves, mas também o próprio volume de água armazenado na Barragem (GRUBEN e LOPES, 2001).

Outro considerável problema da bacia na região seridoense é sua água ser salobra. Isso decorre devido à água da chuva ser insuficiente para eliminar os sais na solução do solo. São as causas da salinização: a composição química da rocha, a própria água de irrigação e a profundidade do solo, pois nesses solos pouco profundos, a água ao evaporar, traz a tona esses sais, aumentando a concentração na superfície. Por isso, a água superficial armazenada pode apresentar-se salinizada ou as do lençol freático, e seu teor varia de 480 a $1.400 \mathrm{mg} / \mathrm{L}$, que é o caso de Currais Novos (RIO GRANDE DO NORTE, Op. Cit), explicando assim o uso de dessalinizadores.

\section{VEGETAÇÃO}

O Seridó é marcado fortemente pela presença de caatingas, nome este herdado do TupiGuarani cujo significado é “floresta branca”. Essa propriedade caracteriza o aspecto da vegetação na estação seca, quando suas folhas caem e revelam os troncos brancos das árvores e arbustos na paisagem seca. É importante notar que o conceito caatinga é melhor descrito se este estiver no plural "caatingas", pois as caatingas não são um bioma homogêneo (LEAL et al, 2003), pelo contrário, este é predominantemente heterogêneo com mudanças que ocorrem muitas vezes em meio a própria predominância de determinadas características.

O ecossistema da Caatinga apresenta essas particularidades devido às condições climáticas extremas em que se desenvolve tais como alta radiação solar, baixa nebulosidade, a mais alta temperatura média anual, baixas taxas de umidade relativa, evapotranspiração potencial mais elevada, e sobretudo, precipitações mais baixas e irregulares (LEAL et al, Op. cit). 
Sendo assim, as caatingas são caracterizadas como florestas arbóreas ou arbustivas, compreendendo principalmente árvores e arbustos baixos. Apresentando mecanismos de defesa às suas condições como espinhos, microfilia (tamanho reduzido dos organismos economiza água e alimentos) e algumas características xerofíticas tais como caules carnudos para armazenar água, folhas reduzidas, raízes longas e a queda das folhas que ao cobrirem o solo, protegem as plantas contra a alta insolação, impedindo que o solo sofra erosão e proteja os seres vivos que nele vivem (MAIA, 2004).

Essa vegetação tende a aparecer em setores com afloramentos de rochas diabásicas (rocha eruptiva intrusiva básica com baixo teor de sílica). Dessa forma, as superfícies das rochas que geram os solos sob a ação do clima são alcalinas, mas as precipitações produzem uma dissolução de bases que são lixiviadas e então um microambiente ácido surge. Por isso, a formação de argilas inicia-se em rochas que sofrem ação do clima, mas o pH principal irá determinar se este é Luvissolos Crômicos, Neossolos Litólicos ou outros devido às condições de geração do material da argila (LEAL et al, Op. cit).

Dessa maneira, associando os tipos de solo com a vegetação existente no Seridó, esta última apresenta na sua fisionomia uma forma raquítica. Possuindo assim, predominantemente espécies como o pereiro (Aspidosderma pyrifolium), a faveleira (Cnidoscolus phyllacanthus), a jurema preta (Mimosa hostilis) e o xique-xique (Pilosocereus gounellei) que é encontrado sobre afloramentos rochosos (RIO GRANDE DO NORTE, 1997) dentre outras espécies.

Apesar das caatingas não terem características verdadeiramente uniformes, estas se distribuem de tal maneira que é possível identificar as áreas principais (onde determinada característica se sobrepõe sobre as outras devido a freqüências que estas ocorrem) das assim chamadas áreas marginais (aonde essas mesmas características assumem nova variação) que vão diminuindo até chegar aos limites com as áreas onde as características das plantas e do meio definem outro tipo de bioma, como em áreas de solos mais profundos ou formação de brejos (SILVA et al, 2003).

Assim, a vegetação do Seridó caracteriza-se, segundo Andrade-Lima (1981), predominantemente em Caatinga arbustiva densa ou aberta. Seus indivíduos apresentam-se próximos entre si, podendo, às vezes, estar agrupados, o que visualmente dá a sensação de organizarem-se em pequenos blocos pela paisagem. Esses blocos são formados por árvores (em torno de $7 \mathrm{~m}$ ) espalhadas em uma matriz arbustiva, que geralmente é formada pela jurema preta devido ao seu caráter pioneiro (MINISTERIO DO MEIO AMBIENTE, 1992). Mesmo assim, na atual degradação que a vegetação seridoense sofreu e continua sofrendo, revela que mesmo tendo uma predominância de árvores e arbustos baixos são possíveis de encontrar indícios de que havia uma quantidade muito maior de arvores altas, como expressa Maia (2004), é uma “caatinga arbórea devastada ao nível de arbusto”, como revela a figura 7 . 


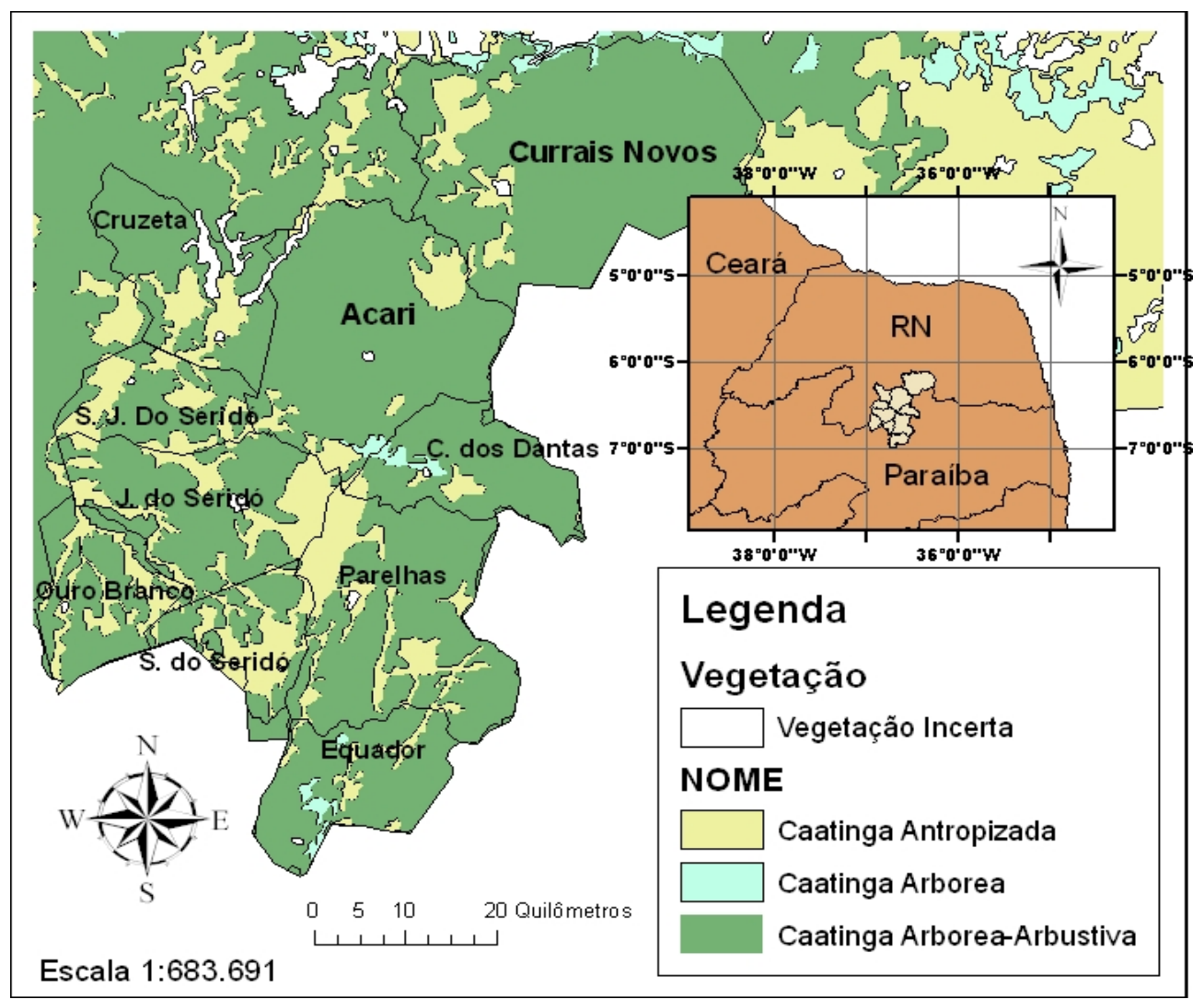

Figura 7: Mapa de vegetação, Bezerra Jr, 2007. Mapa adaptado do SERHID, 2004.

Mesmo assim, a forma como a vegetação se organiza e as espécies que nela podem ser encontradas estão em relação direta com as chuvas, profundidade e permeabilidade do solo (LEAL et al, Op. Cit). Dessa maneira, podemos encontrar áreas com vegetações de predomínio arbóreo ou apenas arbustivo. Por isso, existem algumas espécies que são raras na região, mas que ocorrem de maneira localizada, tais com o angico, a aroeira, o espinheiro e o ipê (MINISTERIO DO MEIO AMBIENTE, Op. Cit).

\section{CONCLUSÃO}

Compreendemos as características geoambientais da região do Seridó Oriental como um sistema integrado. As estruturas geológicas explicam a formação do relevo do Planalto da Borborema e da Depressão Sertaneja. Sua litologia formada por rochas de origem magmática e metamórfica, portanto cristalina, justifica a origem de solos rasos, pedregosos e com pouca drenagem, inviabilizando a sustentabilidade da vegetação não adaptada, o que dificulta a agricultura. Seu clima Semi-Árido reforça esse sistema com suas altas temperaturas, baixas médias pluviométricas, dentre outras características que influenciam o sistema hidrográfico apresentando rios temporários.

Devido a esse déficit hídrico intenso, a região seridoense abriga inúmeras barragens que trazem oportunidades para prática de irrigação, uso humano e turismo no intuito de diminuir as dificuldades socioeconômicas que se apresentam na época da seca.

O bioma da Caatinga liga-se a esse conjunto na medida em que protege o solo contra erosões, facilita a penetração da água no solo e também impede que a água armazenada 
seja evaporada facilmente, mas ao mesmo tempo a vegetação é extremamente frágil a qualquer degradação, sendo poucas as espécies (geralmente as arbustivas) a regenerar-se.

Somando-se a isso, ações antrópicas de desmatamento, assoreamento e má utilização dos recursos naturais contribuem para o processo de desertificação, o que inclui o Seridó Oriental na área de risco de desertificação do país.

Dessa maneira, esses fatores sustentam a importância de entender as características físicas do Seridó para impedir ou amenizar os efeitos das ações que colocam em risco a sustentabilidade sócio-ambiental na região. Cabe destacar que a compreensão integrada destes elementos pode orientar na elaboração de planos de desenvolvimento sustentável, pois como alerta Malvezzi (2007)

O nosso Semi-Árido é o mais chuvoso e populoso do planeta. [...] em média, caem por ano 750 bilhões de m3 de água sobre o nosso Semi-Árido e só temos infra-estrutura para armazenar 36 bilhões, os quais ficam expostos ao processo de evaporação. Portanto, o problema não é a falta de água, mas o seu aproveitamento inteligente.

\section{REFERÊNCIAS BIBLIOGRÁFICAS}

AMARAL, Eufran Ferreira do. Et al; Levantamento de reconhecimento de baixa intensidade dos solos da região de inserção do projeto RECA, Estados de Rondônia, Acre e Amazonas. Rio Branco: EMBRAPA Acre, 2000, p.21.

AYOADE, J.O. Introdução a climatologia para os trópicos. $7^{\circ}$ ed. Rio de Janeiro: Bertrand Brasil, 2001, p.95.

BORGES, Andréa Pereira da Silva. MACIEL, Alex; BACIA DO ATLÂNTICO

NORTE/NORDESTE. Uberlândia: Universidade Federal de Uberlândia, 2003.

CARVALHO, Adailton José Epaminondas de. Et al; Resultados do Seminário de Planejamento Ecorregional da Caatinga. Aldeia: PNE, 2001.

EMBRAPA; Sistema Brasileiro de Classificação de Solos. Recife: EMBRAPA, 1999. Disponível em < http://www.cnps.embrapa.br/sibcs/ > Acessado em 12 de agosto de 2007.

FELIPE, José Lacerda Alves; CARVALHO, Edílson Alves de. Atlas escolar do Rio Grande do Norte. João Pessoa-PB: Grafset, 1999, p.39-46, p.54.

GOMES, F; Desertificação avança no RN. Diário de Natal, Natal, 27 de agosto de 2006, Cidades. p.12.

GRUBEn, Anna. LOPES, Paula Duarte; A Bacia do Rio Piranhas-Açu. Brasília: Projeto marca d’água, 2001, p. p.4 p.10 
GUERRA, Antonio José Teixeira; CUNHA, Sandra Baptista da. Geomorfologia e Meio Ambiente. Rio de Janeiro: Bertrand Brasil, 2004. p.66 p.68-70 p.102 p.92

HÍDRICOS, Secretaria dos Recursos; Programa Estadual de Recursos Hídricos. Natal: Rio Grande do Norte. 2000.

INSTITUTO DE DESENVOLVIMENTO ECONÔMICO E MEIO AMBIENTE. Sigga Web: Mapa de clima do Rio Grande do Norte. Disponível em <http://www.rn.gov.br/secretarias/idema/ > Acessado em 12 de Janeiro de 2008.

LEAL, Inara R. et al. Ecologia e conservação da caatinga. Recife: Ed. Universitária da UFPE, 2003.

MAIA, Gerda Nickel. Caatinga: árvores e arbustos e suas utilidades. São Paulo: D\&Z editora, 2004)

MALVEZZI, Roberto; Semi - Árido: Uma Visão Holística. Brasília: Confea, 2007, p. 106.

NORTE, RIO GRANDE DO; Perfil de municípios. Natal: IDEMA, 2006. Disponível em < http://www.rn.gov.br/secretarias/idema/ > Acessado em 12 de agosto de 2007.

PESSOA, Osvaldo Frota; et al. Biologia nordeste. $2^{\circ}$ Ed. Recife:UFPE, 1971

PRADO, Hélio do; Pedologia Fácil. 2007. Disponível em <

http://www.pedologiafacil.com.br/ > Acessado em 12 de agosto de 2007.

ROSS, Jurandir L. Sanches; Geografia do Brasil. São Paulo: Edusp, 2003, p.57, p.63, p.103-105.

SECRETARIA DE ESTADO DO MEIO AMBIENTE DOS RECURSOS HİDRICOS;

Bacias Hidrográficas do RN. Disponível em < http://www.semarh.rn.gov.br/ >, Acessado em12 de agosto de 2007.

SOUZA, Marcos J. N. de, et al; Condições geo-ambientais do semi-árido brasileiro. Notas e Comunicações de Geografia, Recife, Série B, Nº. 15, p.13, 1996.

VIEIRA, Lúcio Salgado. Manual de morfologia e classificação de solos. $2^{\circ}$ Ed. São Paulo: Agronômica Ceres LTDA, 1983. 